\title{
Lung cancer in lung transplant-management and outcomes
}

\author{
Jesse Rappaport ${ }^{1}$, Usman Ahmad ${ }^{1,2,3}$ \\ ${ }^{1}$ Department of Thoracic and Cardiovascular Surgery, Heart, Vascular, and Thoracic Institute, Cleveland Clinic, Cleveland, OH, USA; ${ }^{2}$ Transplant \\ Institute, Cleveland Clinic, Cleveland, OH, USA; ${ }^{3}$ Taussig Cancer Institute, Cleveland Clinic, Cleveland, OH, USA \\ Contributions: (I) Conception and design: Both authors; (II) Administrative support: U Ahmad; (III) Provision of study materials or patients: Both \\ authors; (IV) Collection and assembly of data: Both authors; (V) Data analysis and interpretation: Both authors; (VI) Manuscript writing: Both \\ authors; (VII) Final approval of manuscript: Both authors. \\ Correspondence to: Usman Ahmad, MD. Department of Thoracic and Cardiovascular Surgery, Cleveland Clinic, 9500 Euclid Avenue/Desk J4-1, \\ Cleveland, OH 44195, USA. Email: ahmadu@ccf.org.
}

\begin{abstract}
Risk factors for lung cancer and end-stage lung disease significantly overlap, therefore index of suspicion for lung cancer should be high in lung transplant candidates. Thoracic surgeons can be faced with clinical scenarios where lung cancer can be discovered in the setting of lung transplant in three distinct categories: (I) transplant candidates who are known to have active or treated lung cancer, (II) transplant recipients who have unexpected incidental cancer discovered in their lung explant, and (III) transplant recipients who develop de novo lung cancer in the lung allograft or native lung after single-lung transplant. While previously considered "lung-limited" disease, bronchioloalveolar carcinoma (BAC) is no longer accepted as an indication for lung transplant due to poor outcomes with high recurrence rates and reclassification as invasive cancer. Any active lung cancer is considered a contraindication to transplant; however, if there is no evidence of disease after 5 years of definitive therapy, lung transplant can be offered. Indeterminate pulmonary nodules are common in lung transplant candidates and should be evaluated in a multidisciplinary fashion. Incidental lung cancer found in explanted lungs portends poor survival. De novo lung cancer after transplant is more common in the native lung after single-lung transplant. Cancer that develops in the allograft can be treated with definitive local therapies and systemic therapies, but long term survival has not yet been demonstrated.
\end{abstract}

Keywords: Lung transplant; lung cancer; outcomes

Received: 19 August 2020; Accepted: 17 February 2021; Published: 25 February 2022.

doi: $10.21037 /$ ccts-20-142

View this article at: http://dx.doi.org/10.21037/ccts-20-142

\section{Introduction}

Lung transplantation provides significant benefit for patients with end-stage lung disease. With $59 \%$ of 5 -year overall survival and significant quality of life improvements, it remains the only definitive treatment for those with advanced lung pathology (1). Continued improvements in organ allocation have decreased waitlist mortality and increased the donor pool, making lung transplantation more appealing for those with end-stage disease.

With similar risk factors including demographics, environmental exposures, and other negative influences, such as smoking, there remains a significant overlap in patients who are at risk of developing lung cancer and endstage lung disease requiring lung transplant. In this context, thoracic surgeons can be faced with clinical scenarios where lung cancer can be discovered in the setting of lung transplant in three distinct categories: (I) transplant candidates who are known to have active or treated lung cancer, (II) transplant recipients who have unexpected incidental cancer discovered in their lung explant, and (III) transplant recipients who develop de novo lung cancer in the lung allograft or native lung after single-lung transplant.

Outcomes for early-stage lung cancer in the general population are favorable, and surgical resection remains the gold standard of treatment (2). Patients with primary 
lung cancer who are deemed medically unfit for standard oncologic surgical resection are relegated to alternative treatment options including limited resection, radiation therapy with or without chemotherapy, or palliative treatment alone. Solid organ transplant recipients, however, have a greater tendency to develop malignancies than the general population, with a 5 -fold increase in lung cancer prevalence in lung transplant recipients (3-5). In single lung transplant recipients, there is a 13 -fold increase in acquiring lung cancer in the native lung compared to the general population (4). Lung cancer arising in the allograft (compared to native lung) has been noted to have a significantly lower prevalence in both single and double lung transplants, however this is still increased from the general population (6-8). Published data have made it abundantly clear that a pulmonary malignancy in the setting of lung transplantation universally results in poor outcomes. Therefore, all efforts in contemporary practice are made to rule out pulmonary malignancy in the transplant candidacy selection process.

Formerly classified as bronchioloalveolar carcinoma (BAC), a specific subtype of adenocarcinoma, was previously considered to have the most potential benefit from transplantation. Limited in their spread to nodal or distant metastases with a slow rate of progression, these cancers were considered to be "lung-limited". Pneumonic spread is common and typically involves multiple lobes in one or both lungs (9). Due to these characteristics, it was postulated that bilateral pneumonectomy followed by lung transplant would be potentially curative for these patients, and patients with BAC were considered for lung transplantation. Further study, conversely, has demonstrated that this is not the case. According to the latest WHO classification changes (10), BAC is now classified as advanced multifocal (diffuse or pneumonic) adenocarcinoma in situ (AIS) or minimally invasive adenocarcinoma (MIA). These tumors include invasive components and would, therefore, not be categorized as "non-invasive, lung limited BAC" and could not be cured by transplantation. To be clear, the term "BAC" is no longer part of lung cancer histologic vernacular. Minimally invasive adenocarcinoma or lepidic adenocarcinoma is typically reserved for and found in the clinical setting of a ground glass lesion.

\section{Patient evaluation and selection}

The recommendations of the International Society for Heart and Lung Transplantation (ISHLT) list malignancy as the first absolute contraindication for transplantation (11). They note the necessity for at least a 2-year, but ideally 5 -year, disease-free interval combined with a low predicted risk of recurrence. The concern for transplantation in the setting of active or recent cancer is due to the subsequent chronic immunosuppression required after transplant for organ preservation and the resulting susceptibility to cancer recurrence or disease progression.

There are three types of cancer presentations in the lung transplant candidacy population: patients with active cancer, patients with previously treated cancer, and patients with indeterminate pulmonary nodules. These candidates must be evaluated thoroughly by both a multidisciplinary lung tumor board and multidisciplinary pulmonary transplant team for suitability for listing and limited risk following transplant $(2,11,12)$.

Active cancer, as discussed, is an absolute contraindication for lung transplantation. Patients with known pneumonic type adenocarcinoma are no longer considered for transplant evaluation until they reach the appropriate disease-free interval. Transplant candidates with known history of definitively treated lung cancer must be classified as disease free. The acceptable disease-free interval is not clearly defined; however, most programs, including our program, require at least five-year disease-free interval, with no evidence of disease at restaging before listing. After tumor board evaluation, these patients are assessed using computerized tomography (CT) of the chest, abdomen, and pelvis, magnetic resonance imaging (MRI) of the brain, and positron emission tomography (PET) scan to clear the candidate for further transplant evaluation.

Pulmonary nodules are common among patients with end-stage lung disease. Any candidate with suspicious or indeterminate lung nodules are presented at our multidisciplinary lung cancer tumor board and subsequently followed for at least 6 to 12 months. These nodules must be critically evaluated with CT scan every 3-6 months to demonstrate stability of both size and character. If pulmonary function allows, the patient must undergo biopsy through bronchoscopic, thoracoscopic, or transthoracic means. While false positives on PET scan are possible with baseline levels of inflammation in these patients (13), it still remains prudent to obtain PET imaging for any suspicious (enlarging or spiculated) nodules. If nodules are without avidity and there has not been any growth after appropriate surveillance, then these patients can be considered for listing. If the clinical risk or suspicion of malignancy remains high, and biopsy is either inconclusive 
or unobtainable, these candidates are deemed not suitable for transplantation. After listing, candidates continue to receive regular CT chest imaging in 3-6 months intervals to ensure that there is no change or growth while awaiting transplant.

\section{Patient outcomes}

\section{Lung transplantation for $B A C$}

The first patient who underwent lung transplant with the indication of lung cancer was described by Dr. Hardy in 1963 (14). This patient died by day 17 due to renal failure and malnutrition complications. A second patient in 1997 underwent bilateral lung transplant for recurrent BAC by Etienne and colleagues (15). This patient had undergone thorough non-invasive testing which demonstrated localized cancer without pleural invasion or adenopathy and ultimately achieved successful results on standard immunosuppression as she remained alive and cancer free 66 months after transplant.

In the subsequent years, three patient series (16-18) describe single or double lung transplants in 2, 7, and 9 patients for the indication of lung cancer with varying results. Two-year survival, reported in all studies, ranged from $50-78 \%$, while five-year survival, reported in only two of three studies, were $14 \%$ and $52 \%$. Recurrence, notably, was common in these studies between $50-75 \%$. Even with a high recurrence and mortality rate, the authors conclude that the transplants offered significant palliation in otherwise fatal and debilitating disease. One additional study (19), looking at all cases of BAC diagnosed at time of, or following transplantation identified 3 patients who had diagnosis at time of surgery and 3 diagnosed during transplant follow-up. In their homogenous group, 2-year survival was only $17 \%$.

Using a survey of lung transplant programs in the ISHLT registry, de Perrot and colleagues (20) identified a $0.9 \%(n=69)$ incidence of bronchogenic carcinoma in explanted lungs over 8,000 transplants. Twenty-six patients underwent lung transplantation for end-stage lung disease secondary to advanced multifocal BAC. Four patients died in the immediate post-transplant period. Of the 22 remaining patients, 13 (59\%) developed recurrence with a median time of 12 months following transplant. Three of these underwent re-transplantation with one perioperative mortality, one death from recurrence at 21 months, and one alive without recurrence at 7 years. Five-year and 10-year survival in the 26 patients were $39 \%$ and $31 \%$, respectively, while 5 -year recurrence-free survival was $35 \%$.

In another study using the United Network for Organ Sharing (UNOS) database, Ahmad and colleagues (12) found 29 patients of 21,553 lung transplants $(0.13 \%)$ during their study period of 1987 to 2010 with the diagnosis of BAC at transplant. By comparison to the general lung transplant population, these patients were more likely to have better forced expiratory volume in 1 second percent predicted $(60 \%$ vs. $35 \%, \mathrm{P}<0.0001)$ and were more likely to receive double-lung transplants (79\% vs. $54 \%, \mathrm{P}=0.006)$. On review of histology, $14(52 \%)$ had pure BAC, $11(41 \%)$ had presence of invasion or other features of adenocarcinoma, and $2(7 \%)$ were found to be predominantly adenocarcinoma. Twenty patients had evaluable lymph nodes; 5 (18.5\%) demonstrated hilar involvement and $4(14.8 \%)$ had mediastinal involvement. These pathologic findings corroborate the incorrect classification of BAC as lung-limited disease.

Thirty-day mortality (10\% vs. $7 \%)$ and 5 -year survival ( $57 \%$ vs. $50 \%$ ) were similar between the BAC group and the overall transplant population, $\mathrm{P}=0.44$ and $\mathrm{P}=0.66$, respectively. For those who had invasion on pathology there was a trend towards worse overall survival (HR 2.24, $\mathrm{P}=0.2$ ). Lymph node involvement did not portend worse survival (HR 1.12, $\mathrm{P}=0.9$ ).

Additional studies reviewing patients who underwent lung transplantation with known cancer diagnosis are listed in Table 1 (12,15-17,20-23). The high recurrence rates across these studies underscore the fact that transplantation in this population is not curative. The change from a "lung-limited" diagnosis of BAC to AIS and MIA as invasive entities helps to elucidate the reason for these poor outcomes (10).

\section{Incidental cancers in explant}

Incidental cancers at time of transplant have been found at a rate around $0.5-2.0 \%$ (Table 2) $(13,19,20,24-30)$.

The additional 43 patients identified from de Perrot and colleagues' study (20) had incidentally found cancer in the explanted lungs. They were transplanted with majority indications of emphysema $(n=26)$ and idiopathic pulmonary fibrosis $(n=11)$. Based on TNM staging, they noted 19 with T1N0, 3 with T2N0, 12 with T2N1, and 2 with T1N2 or T2N2. Multifocal BAC was noted in 6 patients with single lung involvement and bilateral in 1 patient. Five patients with stage I disease died with recurrent disease within 12 months after transplantation. Nine patients with stage II 
Table 1 Lung transplant for lung cancer*

\begin{tabular}{|c|c|c|c|c|c|}
\hline Author, year & Patients (n) & Tumor diagnosis & Transplant type & Recurrence rate & Overall survival \\
\hline \multirow[t]{2}{*}{ Garver et al. (16), 1999} & 7 & BAC & $29 \%$ Single & $57 \%$ & $71 \% 2-y r$ \\
\hline & & & $71 \%$ Double & & $14 \% 5-y r$ \\
\hline Paloyan et al. (17), 2000 & 2 & BAC & $100 \%$ Double & $50 \%$ & $50 \% 2-y r$ \\
\hline \multirow[t]{2}{*}{ Zorn et al. (18), 2003} & 9 & BAC & $22 \%$ Single & $75 \%$ & $78 \% 2-y r$ \\
\hline & & & $78 \%$ Double & & $52 \% 5-y r$ \\
\hline \multirow[t]{2}{*}{ de Perrot et al. (20), 2004} & 26 & BAC & $35 \%$ Single & $59 \%$ & $60 \% 2-y r$ \\
\hline & & & $65 \%$ Double & & $45 \% 5-y r$ \\
\hline
\end{tabular}

*, Reprinted from Thoracic Surgery Clinics, 24/4, Kachala SS, Murthy SC, Lung transplantation for multifocal lung adenocarcinoma (multifocal lung carcinoma), 485-91, 2014, with permission from Elsevier. BAC, bronchioloalveolar carcinoma; ACA, adenocarcinoma.

Table 2 Incidentally found lung cancer

\begin{tabular}{|c|c|c|c|c|c|}
\hline Author, year & Patients (n) & Tumor diagnosis & Transplant type & Recurrence rate & Overall survival \\
\hline Arcasoy et al. (19), 2001 & 2 & NSCLC & $50 \%$ Single; $50 \%$ Double & - & $20 \% 2-y r$ \\
\hline de Perrot et al. (20), 2004 & 43 & BAC, NSCLC & - & $42 \%$ & $28 \%$ 2-yr; 7\% 5-yr \\
\hline Strollo et al. (13), 2013 & 22 & NSCLC & 23\% Single; $77 \%$ Double & $18 \%$ & - \\
\hline Grewal et al. (26), 2015 & 6 & ACA only & - & $67 \%$ & $17 \% 2-y r$ \\
\hline Panchabhai et al. (27), 2018 & 24 & NSCLC & $54 \%$ Single; $46 \%$ Double & $33 \%$ & $45 \% 2-y r$ \\
\hline Chatron et al. (28), 2019 & 8 & NSCLC & 100\% Double & $13 \%$ & - \\
\hline Ahmad et al. (29), 2019 & 29 & NSCLC, SCLC & $52 \%$ Single; 48\% Double & $32 \%$ & $30 \% 2-y r ; 14 \% 5-y r$ \\
\hline
\end{tabular}

ACA, adenocarcinoma; NSCLC, non-small cell lung cancer; BAC, bronchioloalveolar carcinoma; SCLC, small cell lung cancer.

or III died from recurrence with a median of 8 months, and, of the seven BAC patients, three recurred.

Our recently reported institutional data (29) found 31 explants with unexpected malignancies out of 1,710 lung transplants. Twenty-nine of these were primary lung cancer, one with metastatic colon cancer, and one with mucosaassociated lymphoid tissue lymphoma. Transplant diagnoses included chronic obstructive pulmonary disease $(n=15)$ and interstitial pulmonary fibrosis $(n=16)$ with a mean LAS of 38.4. Adenocarcinoma was the most common histologic subtype $(59 \%)$ and the majority were stage $I(n=15)$. The remaining 14 patients included 10 stage II, 2 stage IIIA, and 2 stage $\mathrm{IV}$. One patient was categorized retrospectively as stage IV given primary non-small cell lung cancer (NSCLC) in contralateral mediastinal nodes and a spinal lesion that rapidly enlarged following transplant. The other patient with stage IV disease was transplanted during an acute exacerbation of IPF on venovenous extracorporeal oxygenation and was found to have mucinous adenocarcinoma in all lobes after explantation.

Recurrence or progression of disease was noted in 8 patients with a median time to recurrence of 14 months. 
Most progression of disease was noted to be extrathoracic spread $(n=6)$ and all 8 of these patients succumbed to their cancer. Median time from recurrence to death was only 4.5 months. Those with stage I and II disease had 55\% 5 -year recurrence-free survival. Overall survival for stage I disease was $87 \%, 26 \%$, and $17 \%$ at 1,3 , and 5 years, respectively, while stage II disease overall survival was $78 \%$ and $11 \%$ at 1 and 3 years. When all patients were considered as a group, 1-, 3-, and 5-year survival was $78 \%$, $18 \%$, and $14 \%$, respectively.

Strollo and colleagues (13) assessed incidentally found cancers at time of transplant at their own institution and found out of 759 lung transplant recipients, 22 cases (2.9\%) had incidental cancer, 17 of which were lung cancer. They retrospectively reviewed CT scans and reports completed prior to transplant, which occurred at a mean of 4 months prior. They were able to correctly identify 10 of the 22 lesions retrospectively, and found the reports to have a miss rate for CT-positive findings of $20 \%$. Their study underlines the difficult nature of identifying occult malignancies with concurrent diffuse lung disease and multiple CT abnormalities in this patient population.

Ultimately cancers found in lung explants, while typically earlier stage, still carry a poor prognosis. At our institution, when cancer is diagnosed in the explanted lung, subsequent work-up includes MRI of the brain and PET scan at 46 weeks following transplant to evaluate for metastatic disease. Follow-up CT scans are performed every 6 months. Medical oncology evaluation is routinely obtained in these patients, but treatment options are severely limited by chemotoxicity (specifically nephrotoxicity) and physical debilitation. Modified chemotherapy regimens are used in this patient population due to relatively poor outcomes with full-dose systemic chemotherapy (25).

\section{New lung cancer after transplantation}

The development of cancer after solid organ transplant is significantly increased from that of the general population. A combination of chronic immunosuppression and underlying risk factors makes the development of lung cancer after lung transplant a possible complication. Lung cancer found after transplant can develop in the native lung of single-lung recipients or in the lung allograft in single or double lung recipients. Tumors in the allograft may arise from an undetected primary or secondary malignancy from the donor at time of transplant or a new primary or secondary malignancy from the recipient after transplant
(Table 3) (4,5,19,24-26,28,31-36).

Cancers arising in the lung allograft as an undiagnosed donor cancer is rare, likely attributable to rigorous donor selection criteria $(8,37,38)$. Limited donor pools have led to increasing use of expanded donors with older age. The increased risk that this poses must be continually assessed.

In a single center study of 847 lung transplant patients from 2005 to 2013 (25), 17 (12\%) were diagnosed with lung cancer. Eight of the cases were diagnosed in the explanted lung, 5 were diagnosed in the native remaining lung, 3 were found in the transplanted allograft, and 1 was unknown. Stage I/II were most common $(n=11)$, one patient had stage III, and five were diagnosed at stage IV. NSCLC was more common $(\mathrm{n}=15)$ than small cell lung cancer (SCLC). Diagnosis of malignancy for those detected in the native (not explanted) lung or allograft was at a median of 26.7 months after transplant.

Of the 17 patients, 12 had potential curable disease. For the five patients diagnosed with stage I disease in the explanted lung, no adjuvant treatment was pursed, and two later developed recurrences in the transplanted lung. Two of three patients diagnosed with stage II disease in their explanted lung underwent adjuvant chemotherapy. For one patient with stage II disease in their native lung, lobectomy was performed. This patient developed metastatic disease after 5 months and died 7 months after initiation of chemotherapy. In two patients with cancer in the allograft (1 stage I SCLC, 1 stage II NSCLC) radiation followed by chemotherapy was employed. Median survival for those with cancer in their explanted lung was 24 months compared to 4.8 months in those that developed cancer after transplantation.

In the Transplant Cancer Match (TCM) study combing the US Scientific Registry of Transplant Recipients (SRTR) with 17 state and regional cancer registries (4), 8,993 firsttime lung transplant recipients were evaluated. During follow-up, 183 cases of lung cancer were found at a median of 3.9 years. The vast majority of cases $(n=169,92 \%)$ were in single-lung recipients and the majority of those were in the native lung ( $\mathrm{n}=153,91 \%)$. Two-year overall survival after transplant diagnosis was around $20 \%$.

New cancer diagnosis after transplant portends worse prognosis. A significant portion of post-lung transplant lung cancer is late-stage on presentation even in this closely followed population. For early-stage disease, surgery or stereotactic body radiation therapy (SBRT) may provide some benefit, but overall survival is significantly shortened compared to the non-transplant population. 
Table 3 Lung cancer after lung transplant

\begin{tabular}{|c|c|c|c|c|c|c|}
\hline Author, Year & Patients (n) & Tumor diagnosis & Transplant type & Tumor location & Stage $>I I I A^{*}$ & Overall survival \\
\hline Arcasoy et al. (19), 2001 & 4 & NSCLC & $100 \%$ Single & $100 \%$ Native & $50 \%$ & $20 \% 2-y r$ \\
\hline Collins et al. (31), 2002 & 24 & NSCLC, SCLC & $100 \%$ Single & 100\% Native & $44 \%$ & - \\
\hline Dickson et al. (32), 2006 & 9 & NSCLC & $100 \%$ Single & $100 \%$ Native & $33 \%$ & $25 \% 5-y r$ \\
\hline Raviv et al. (34), 2011 & 7 & NSCLC & $100 \%$ Single & $\begin{array}{l}\text { 14\% Allograft; } \\
86 \% \text { Native }\end{array}$ & $71 \%$ & - \\
\hline Yserbyt et al. (35), 2012 & 13 & NSCLC, SCLC & $\begin{array}{l}69 \% \text { Single; } \\
31 \% \text { Double }\end{array}$ & $\begin{array}{l}31 \% \text { Allograft; } \\
69 \% \text { Native }\end{array}$ & $62 \%$ & $40 \% 5-y r$ \\
\hline Du et al. (25), 2015 & 9 & NSCLC, SCLC & $\begin{array}{l}53 \% \text { Single; } \\
47 \% \text { Double }\end{array}$ & $\begin{array}{l}\text { 55\% Allograft; } \\
\text { 45\% Native }\end{array}$ & $67 \%$ & - \\
\hline $\begin{array}{l}\text { Pérez-Callejo et al. (5), } \\
2018\end{array}$ & 18 & NSCLC, SCLC & $\begin{array}{l}\text { 70\% Single; } \\
\text { 30\% Double }\end{array}$ & $\begin{array}{l}33 \% \text { Allograft; } \\
67 \% \text { Native }\end{array}$ & $70 \%$ & $57 \% 5-y r$ \\
\hline Chatron et al. (28), 2019 & 11 & NSCLC & $\begin{array}{l}82 \% \text { Single; } \\
18 \% \text { Double }\end{array}$ & $\begin{array}{l}\text { 27\% Allograft; } \\
\text { 73\% Native }\end{array}$ & $55 \%$ & $18 \% 2-y r$ \\
\hline Triplette et al. (4), 2019 & 183 & NSCLC, SCLC & $\begin{array}{l}\text { 45\% Single; } \\
55 \% \text { Double }\end{array}$ & $\begin{array}{l}\text { 16\% Allograft; } \\
84 \% \text { Native }\end{array}$ & $46 \%$ & $20 \% 2-y r$ \\
\hline
\end{tabular}

${ }^{*}$, at diagnosis. SCC, squamous cell carcinoma; NSCLC, non-small cell lung cancer; SCLC, small cell lung cancer.

\section{Conclusions}

Lung transplantation in the setting of known active lung cancer has a high rate of recurrence with poor posttransplant outcomes and thus is an absolute contraindication for lung transplant listing. With proper patient selection, multidisciplinary lung cancer tumor board and lung transplant selection committee evaluation, and significant attention to follow up, appropriate candidates with previously treated lung cancer and low recurrence risk can be safely listed and transplanted. Incidentally found tumors at time of transplantation have variable outcomes based on stage and histology, and, even with a rate around $2 \%$, underline the importance of thorough explant histologic evaluation.

\section{Acknowledgments}

Funding: This study was supported in part by the Drs
Sidney and Becca Fleischer Heart and Vascular Education Chair and the Daniel and Karen Lee Endowed Chair in Thoracic Surgery.

\section{Footnote}

Provenance and Peer Review: This article was commissioned by the Guest Editors (Jing Yu Chen and Michael Hsin) for the series "Highlights of the First International Symposium on Lung transplantation, Wuxi, China, 2019" published in Current Challenges in Thoracic Surgery. The article has undergone external peer review.

Conflicts of Interest: Both authors have completed the ICMJE uniform disclosure form (available at https://ccts.amegroups. com/article/view/10.21037/ccts-20-142/coif). The series "Highlights of the First International Symposium on Lung transplantation, Wuxi, China, 2019" was commissioned by 
the editorial office without any funding or sponsorship. The authors have no other conflicts of interest to declare.

Ethical Statement: The authors are accountable for all aspects of the work in ensuring that questions related to the accuracy or integrity of any part of the work are appropriately investigated and resolved.

Open Access Statement: This is an Open Access article distributed in accordance with the Creative Commons Attribution-NonCommercial-NoDerivs 4.0 International License (CC BY-NC-ND 4.0), which permits the noncommercial replication and distribution of the article with the strict proviso that no changes or edits are made and the original work is properly cited (including links to both the formal publication through the relevant DOI and the license). See: https://creativecommons.org/licenses/by-nc-nd/4.0/.

\section{References}

1. Yusen RD, Edwards LB, Dipchand AI, et al. The Registry of the International Society for Heart and Lung Transplantation: Thirty-third Adult Lung and HeartLung Transplant Report-2016; Focus Theme: Primary Diagnostic Indications for Transplant. J Heart Lung Transplant 2016;35:1170-84.

2. Howington JA, Blum MG, Chang AC, et al. Treatment of stage I and II non-small cell lung cancer: Diagnosis and management of lung cancer, 3rd ed: American college of chest physicians evidence-based clinical practice guidelines. Chest 2013;143:e278S-313S.

3. Engels EA, Pfeiffer RM, Fraumeni JF, et al. Spectrum of cancer risk among US solid organ transplant recipients. JAMA 2011;306:1891-901.

4. Triplette M, Crothers K, Mahale P, et al. Risk of lung cancer in lung transplant recipients in the United States. Am J Transplant 2019;19:1478-90.

5. Pérez-Callejo D, Torrente M, Parejo C, et al. Lung cancer in lung transplantation: Incidence and outcome. Postgrad Med J 2018;94:15-9.

6. Olland A, Falcoz PE, Massard G. Malignancies after lung transplantation. J Thorac Dis 2018;10:3132-40.

7. Van Raemdonck D, Vos R, Yserbyt J, et al. Lung cancer: A rare indication for, but frequent complication after lung transplantation. J Thorac Dis 2016;8:S915-24.

8. Magruder JT, Crawford TC, Grimm JC, et al. Risk Factors for De Novo Malignancy Following Lung Transplantation. Am J Transplant 2017;17:227-38.
9. Travis WD, Brambilla E, Noguchi M, et al. International Association for the Study of Lung Cancer/American Thoracic Society/European Respiratory Society: International multidisciplinary classification of lung adenocarcinoma - An executive summary. Proc Am Thorac Soc 2011;8:381-5.

10. Travis WD, Brambilla E, Nicholson AG, et al. The 2015 World Health Organization Classification of Lung Tumors. J Thorac Oncol 2015;10:1243-60.

11. Weill D, Benden C, Corris PA, et al. A consensus document for the selection of lung transplant candidates: 2014 - An update from the Pulmonary Transplantation Council of the International Society for Heart and Lung Transplantation. J Heart Lung Transplant 2015;34:1-15.

12. Ahmad U, Wang Z, Bryant AS, et al. Outcomes for lung transplantation for lung cancer in the United Network for Organ Sharing registry. Ann Thorac Surg 2012;94:935-40.

13. Strollo DC, Dacic S, Ocak I, et al. Malignancies incidentally detected at lung transplantation: Radiologic and pathologic features. AJR Am J Roentgenol 2013;201:108-16.

14. Hardy JD, Webb WR, Dalton ML, et al. Lung Homotransplantation in Man: Report of the Initial Case. JAMA 1963;186:1065-74.

15. Etienne B, Bertocchi M, Gamondes JP, et al. Successful double-lung transplantation for bronchioloalveolar carcinoma. Chest 1997;112:1423-4.

16. Garver RI, Zorn GL, Wu X, et al. Recurrence of bronchioloalveolar carcinoma in transplanted lungs. $\mathrm{N}$ Engl J Med 1999;340:1071-4.

17. Paloyan EB, Swinnen LJ, Montoya A, et al. Lung transplantation for advanced bronchioloalveolar carcinoma confined to the lungs. Transplantation 2000;69:2446-8.

18. Zorn GL, McGiffin DC, Young KR, et al. Pulmonary transplantation for advanced bronchioloalveolar carcinoma. J Thorac Cardiovasc Surg 2003;125:45-8.

19. Arcasoy SM, Hersh C, Christie JD, et al. Bronchogenic carcinoma complicating lung transplantation. J Heart Lung Transplant 2001;20:1044-53.

20. de Perrot M, Chernenko S, Waddell TK, et al. Role of Lung Transplantation in the Treatment of Bronchogenic Carcinomas for Patients With End-Stage Pulmonary Disease. J Clin Oncol 2004;22:4351-6.

21. Geltner C, Jamnig H, Bucher B, et al. Lung Transplantation for Bronchiolo-Alveolar Lung Carcinoma. Lung Cancer 2002;37:S27.

22. Nakajima T, Cypel M, de Perrot $M$, et al. Retrospective Analysis of Lung Transplant Recipients Found to Have 
Unexpected Lung Cancer in Explanted Lungs. Semin Thorac Cardiovasc Surg 2015;27:9-14.

23. Kachala SS, Murthy SC. Lung transplantation for multifocal lung adenocarcinoma (multifocal lung carcinoma). Thorac Surg Clin 2014;24:485-91.

24. Stagner LD, Allenspach LL, Hogan KK, et al. Bronchogenic carcinoma in lung transplant recipients. J Heart Lung Transplant 2001;20:908-11.

25. Du L, Pennell NA, Elson P, et al. Lung cancer treatment outcomes in recipients of lung transplant. Transl Lung Cancer Res 2015;4:784-91.

26. Grewal AS, Padera RF, Boukedes S, et al. Prevalence and outcome of lung cancer in lung transplant recipients. Respir Med 2015;109:427-33.

27. Panchabhai TS, Arrossi AV, Patil PD, et al. Unexpected Neoplasms in Lungs Explanted From Lung Transplant Recipients: A Single-Center Experience and Review of Literature. Transplant Proc 2018;50:234-40.

28. Chatron E, Dégot T, Salvaterra E, et al. Lung cancer after lung transplantation: An analysis of 25 years of experience in a single institution. Clin Transplant 2019;33:e13446.

29. Ahmad U, Hakim AH, Tang A, et al. Patterns of Recurrence and Overall Survival in Incidental Lung Cancer in Explanted Lungs. Ann Thorac Surg 2019;107:891-96.

30. Abrahams NA, Meziane $M$, Ramalingam $P$, et al. Incidence of primary neoplasms in explanted lungs: Long-term

doi: $10.21037 /$ ccts-20-142

Cite this article as: Rappaport J, Ahmad U. Lung cancer in lung transplant-management and outcomes. Curr Chall Thorac Surg 2022;4:7. follow-up from 214 lung transplant patients. Transplant Proc 2004;36:2808-11.

31. Collins J, Kazerooni EA, Lacomis J, et al. Bronchogenic carcinoma after lung transplantation: Frequency, clinical characteristics, and imaging findings. Radiology 2002;224:131-8.

32. Dickson RP, Davis RD, Rea JB, Palmer SM. High Frequency of Bronchogenic Carcinoma After Singlelung Transplantation. J Heart Lung Transplant 2006;25:1297-301.

33. Minai OA, Shah S, Mazzone P, et al. Bronchogenic carcinoma after lung transplantation: Characteristics and outcomes. J Thorac Oncol 2008;3:1404-9.

34. Raviv Y, Shitrit D, Amital A, et al. Lung cancer in lung transplant recipients: Experience of a tertiary hospital and literature review. Lung Cancer 2011;74:280-3.

35. Yserbyt J, Verleden GM, Dupont LJ, et al. Bronchial carcinoma after lung transplantation: A single-center experience. J Heart Lung Transplant 2012;31:585-90.

36. Espinosa D, Baamonde C, Illana J, et al. Lung cancer in patients with lung transplants. In: Transplantation Proceedings. Vol 44. Elsevier; 2012:2118-9.

37. Desai R, Collett D, Watson CJ, et al. Cancer transmission from organ donors-unavoidable but low risk. Transplantation 2012;94:1200-7.

38. Hutchinson J. Donor malignancies. Transplantation 2015;99:270-1. 